\title{
Green Drying of Tomato Slices by Modified Indirect Air Solar Heater
}

\author{
Walaa Saadeh $^{1)}$, Jamil Haddad ${ }^{2)}$, Fadi Anton ${ }^{2)}$ \\ ${ }^{1)}$ Chemical Engineering Department Faculty of Engineering Technology, Al-Balqa Applied University, P. O. Box 15008, 11134 Jordan \\ ${ }^{2)}$ Mechanical Engineering Department Faculty of Engineering Technology, Al-Balqa Applied University, P. O. Box 15008, 11134 Jordan
}

This work aims to utilize the enormous solar energy potential in Jordan in drying agricultural products (Tomato). This study presents a proposed model of the indirect solar dryer with an innovative design by adding mirrors, a nozzle, and a fan to improve the tomato slices' drying process. The effect of these modifications has been investigated. Interestingly, the solar system design reduced the moisture content in these agricultural products to increase shelf life and improve its quality. Moreover, it can be concluded that the addition of nozzles and mirrors improves the solar dryer performance such that higher heat power absorption up to $6.5 \mathrm{~kW}$, higher effectiveness up to $92 \%$, higher drying ratio up to $90 \%$, and reduction in the required drying time by three hours.

Keywords: green drying; solar heater; Indirect solar dryer; natural convection dryer..

\section{Introduction}

Several techniques are used to preserve food, but drying is recognized as one of the oldest and most efficient methods for foodstuffs preservation and storage purposes (Hawlader et al., 2006). The primary function of drying is reducing the food's moisture content, which exceeds $90 \%$ in some cases (Baradey et al., 2016). Water content can lead to severe consequences concerning food corruption and putrefaction due to increasing the microorganisms' growth (Turkiewicz et al., 2019; Zhang et al., 2006). However, drying leads to inhibit microbial activity and keep foods for a long time. Furthermore, drying reduces the weight of the agricultural products and its size, hence reducing transportation costs. The process of drying is mainly done by applying heat to food, which forces the moisture to be transferred from the interior of the material to its surface and then its removal into the surrounding air till the vapor pressure of water in the food becomes equal to the partial pressure of water in the air. At this point, the moisture content is at its minimum value to which the food can be dried, and it is called the equilibrium moisture content under the given conditions for the drying process (Singh et al., 2011). However, the hygroscopic materials cannot be dried to zero moisture level, unlike the nonhygroscopic materials.

Various external parameters play an important role in affecting the drying process, such as temperature, air humidity, airstream velocity, solar radiation, properties of the drying material, initial moisture content, and total mass of the product (Bena and Fuller, 2002; Wilkins et al., 2018). Drying is a combination of mass and heat transfer processes that essentially requires providing energy. Solar energy is one of the most commonly used energy sources since it is clean, environment-friendly, abundantly available, renewable, free of cost, efficient, and effective in replacing other conventional sources (Belessiotis and Delyannis, 2011; Kumar and Rosen, 2011). The drying method that mainly depends on such kind of energy can be considered as a green drying method that can be several times more efficient and less costly than other methods while contributing to a sustainable society and preserving the environment (Alves-Filho, 2018). It can also increase the productivity of fruits and vegetables and improve quality and quantity. The most straightforward application of this energy type is to convert it into heat (Zhang et al., 2006). According to the Ministry of Agriculture reports in Jordan, it is considered among the top 10 in tomato cultivation. Still, it suffers from high harvesting loss due to the unexpected temperature changes in the winter season. In 2015, for example, the tomato production average was $10-16$ tonnes from one greenhouse in the winter, but in April, the Amount was dropped to only 3 tonnes. However, the annual production of fruits and vegetables in Jordan is over 3 million tonnes. The high loss rate in this huge Amount could be avoided by using drying techniques, as suggested in this study (Al Emam, 2015). For the past five years, there has been a rapid rise in the use of different modified types of dryers, significantly the indirect type solar dryer, either it is natural circulation type (passive mode) or forced circulation type (active mode) (Erick César et al., 2020). All of its types completely protect the dried food from direct ultra-violet radiation and against dust, rain, and insects compared to open sun drying (Esper and Mühlbauer, 1998).

Received on July 7, 2020; accepted on November 28, 2020, correspondence concerning this article should be addressed (E-email address: Walaa.saadeh@bau.edu.jo, ORCiD ID for Walaa Saadeh https://orcid.org/0000-0001-5055-0092. 
The solar dryer's performance firmly depends on the incident solar radiation. It affects the drying time based on its effect on the temperature of both the solar dryer collector and the dryer chamber (Hassanain, 2009). In the Middle East Region, especially in Jordan, there are 330 sunny days yearly, and the average solar radiation intensity is $5.5 \mathrm{~kW} / \mathrm{m}^{2}$.day. According to this relatively high incident, radiation energy, which is more than the average world amount that was reported to be $3.82 \mathrm{~kW} / \mathrm{m}^{2}$.day, the selection of solar energy for drying can be considered an economical choice (Qasaimeh, 2012). Regarding indirect solar dryers, they simply consist of a solar air collector to increase the inlet air temperature, a chamber to keep the drying material, a chimney to provide the required draft force. To force the air at the inlet or the dryer's outlet does not appear to be modifying the subject an electric fan or blower., an electric fan or blower can be added (Arunsandeep et al., 2018). There are several examples of using such drying systems for various types of food in the literature, but with different design modifications. Some preliminary work was carried out in 1998 (Bonaparte et al., 1998) to compare cocoa beans' drying using open sun drier, direct solar drier, and indirect solar drier. The beans were highly exposed to external mold in the free sun drier and were lower in their outer appearance. Furthermore, the direct drier's beans showed the most inferior quality, but the indirect drier showed the highest. Maiti et al. (Maiti et al., 2011) carried out experiments on drying $1 \mathrm{~kg}$ of Indian wafer called "papad" using natural convection indirect solar dryer fitted with reflectors. The collector's efficiency was increased from $40 \%$ to $58.5 \%$ due to using the mirror's reflectors. The final product's moisture content was reduced to $12 \%$, and the efficiency of the drying was initially $16.3 \%$, but on average, it was $4.1 \%$. Parikh and Agrawal (Parikh and Agrawal, 2012) conducted experiments on $2 \mathrm{~kg}$ drying chili and $1 \mathrm{~kg}$ potato chips using a flat plate collector attached to a double shelf cabinet dryer with a glazing cover for improving the efficiency. Glass glazing increased the efficiency from a range of $9-12 \%$ to $23.7 \%$ compared to polycarbonate glazing which increased the efficiency to $18.5 \%$. Experiments on using concentrating solar panels were performed on drying Roma tomatoes in 2012 by a group of researchers (Stiling et al., 2012). Based on their work, the drying time was reduced by $27 \%$ due to the temperature increase of about $10^{\circ} \mathrm{C}$. In 2017 , a natural convection solar dryer was designed by Al-Busoul (Al-Busoul, 2017), with a capacity of $100 \mathrm{~kg}$ of sliced apples. The moisture content of the final product was reduced to $10 \%$ within two days. A recent study was conducted on drying a relatively large amount of $7.45 \mathrm{~kg}$ of tomatoes slices in 2019 in an indirect solar dryer (Erick César et al., 2020). The moisture content was reduced from 93.81\% to $6.54 \%$ within 26 hours, and the average thermal efficiency of the solar collector was found approx. 53.9\%, but the drying efficiency was estimated at $8.80 \%$. Furthermore, there are much work on the potential of using forced convection solar dryers has been carried out (Bennamoun, 2013; Hassanain, 2009; Schirmer et al., 1996; Sorour and Elmesery, 2014; Tiris et al., 1996), as they show higher efficiency compared to the natural convection solar dryers in addition to easier control for the drying process by controlling air temperature or airflow rate using blower or fan. However, there are still some critical issues regarding the fabrication, operational, and maintenance costs compared with the natural convection solar dryers. Abhay et al. (Lingayat et al., 2017) designed and tested an indirect solar dryer for drying $2 \mathrm{~kg}$ of banana. This design was provided with a $\mathrm{V}$-shaped corrugated absorber plate and a multi trays chamber. As a result, the moisture content was reduced from $78 \%$ to approximately. $18 \%$, and the average efficiency of the collector and the chamber were estimated to be $31.50 \%$ and $22.38 \%$, respectively. Also, it was noticed that the drying air temperature is the most important factor that strongly influence the drying process, followed by the air humidity and velocity as well. Moreover, several studies investigated the usage of forced convective V-grooved collectors and found that they have a considerable effect on the air flow rate and hence affect the thermal efficiency and drying rate (Al-Juamily et al., 2007; Samuel, 2006). In this study, the performance of a modified design for a natural convection indirect type solar dryer was investigated by the addition of mirrors, nozzle, and a fan. Heat power, effectiveness, relative humidity, weight losses, and drying ratio have been studied and analyzed for drying tomato slices.

\section{Materials and Methods}

\subsection{Raw material}

A sufficient amount of tomatoes $(350 \mathrm{~g})$ were obtained from the local market of Zarqa city. The initial moisture content was about $83 \%$ wet basis $(w b)$. They were selected based on their similarity in size, color, and maturity. In preparation for the drying process, the tomato samples were washed to remove dust and undesired foreign materials. The water, which remained after the washing process, was released by a cotton cloth. After that, the tomatoes were chipped into uniform slices to be dried directly (the slice thickness $1.5 \mathrm{~cm}$ ). The drying rate depends on sectioning on the tomato to dry, and basically, the tomato surface is in contact with the air (Ben Slama and Combarnous, 2011).

\subsection{Equipment description}

The new solar dryer model operated in natural convection mode and consists of two fundamental parts, a flat corrugated solar collector for heating the inlet air by capturing solar radiation and transferring this thermal energy to the air, and a drying chamber 
with two perforated trays (the area of each tray is $0.724 \mathrm{~m}^{2}$ ) which contain the tomato slices as shown in Figure 1 (a) and (b). However, the food inlet part is a door that opens and closes to insert samples into the system. To maximize the indirect solar radiation, the solar collector was oriented toward the south direction, with a tilt angle of $35^{\circ}$. The drying chamber was designed using double glass ( $6 \mathrm{~mm}$ of the clear glass followed by $12 \mathrm{~mm}$ air gap, then $6 \mathrm{~mm}$ of clear glass) that can absorb the heat from surrounding (solar radiation) and keep it inside. Due to this design, the required heat inside the chamber for the drying process can be increased. Several modifications are shown in Fig. 1 (c) and (d) have been added to the module to improve the drying process, such as:

1. Chimney: To allow hot, humid air to come out of the solar module to avoid heat accumulation inside the device, which adjusts the relative humidity of the device.
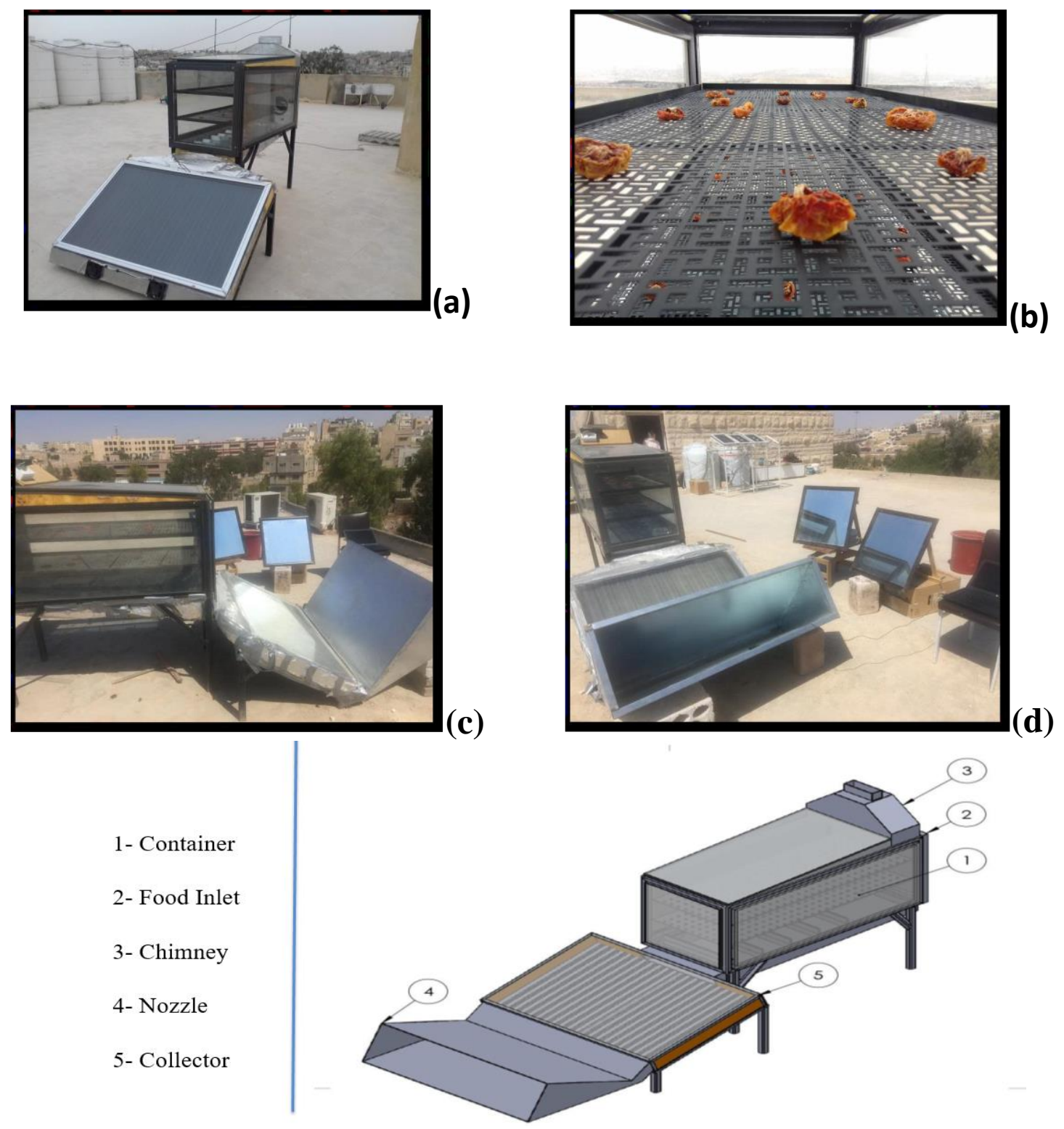

(e)

Fig. 1 (a) The drying system (the solar collector and the drying chamber) before the addition of mirrors and nozzle; (b) Tomatoes inside the drying chamber (c) and (d) The drying system after the addition of mirrors and nozzle; (e) Parts of the drying system. 
2. A nozzle: fixed in front of the solar collector; to increase the velocity of inlet air to enter the drying chamber at a higher speed leads the air to be regularly distributed on the container shelves.

3. The mirrors: placed on the solar collector's sidewalls to collect solar radiation.

4. A Fan: placed at the chimney outlet to pull the outlet air, which flows from the drying chamber to outside; the fan speed was $3.28 \mathrm{~m} / \mathrm{s}$. Moreover, the absorber plate is corrugated to increase the air turbulence, enhancing the heat transfer rate. Fig. 1 (e) shows a schematic sketch for the solar module parts.

\subsection{Instrumentation}

The natural convection indirect type solar dryer was instrumented as follows: The ambient temperature, the inlet air temperature to the nozzle, and the outlet air temperature from the chimney are measured with a temperature sensor (Elma DT171), which is a small intelligent data logger with a built-in sensor for both temperature and humidity. It contains a real-time clock and has a considerable memory size that can store 16,000 datasets, in addition to a comfortable and quickly programmed data logging software by merely using USB connection. The measurement control and documentation can be performed easily by transferring the records to a computer. Additionally, this sensor is used as a humidity sensor to measure the air humidity inside and outside the chamber. A digital anemometer (Benetech GM816A) was used to measure the air velocity at the inlet and the outlet, wind speed, and temperature. A digital balance (SF-400) was used to measure the samples' weight before and after drying. Table 1 demonstrates the characteristics of each instrument.

\subsection{Experimental procedure}

This study conducted in Jordan, particularly in "Zarqa" (32 $04^{\prime} 21.90 "$ N, 36 05' 16.66" $\mathrm{E})$; therefore, many variables affect the drying process have been controlled in order to get accurate results, such as temperature, humidity, air velocity, the direction of air and time. The prepared tomato slices' weight was recorded using the digital balance, as shown in Figure 2, the prepared pieces placed in the drying container trays inlet. The air temperature, humidity, and air velocity were measured for both inlet and outlet streams using the instruments mentioned above. The measurements were recorded at four-time intervals during the day; 9:00 am, 12:00 pm, 3:00 pm, and 5:00 pm in April 2019. The inlet air with $33.4{ }^{\circ} \mathrm{C}$ average temperature entered the solar collector at a higher temperature of $60{ }^{\circ} \mathrm{C}$, passing through the nozzle. Due to this temperature difference, the inlet air was heated and flowed in natural convection mode into the tomato slices container. In the drying chamber, the heat transferred from the heated air to the tomato slices, which led to reduced moisture content due to mass and heat transfer processes. The air received the moisture from the tomato slices and left the chamber, passing through the chimney as humid air with an average outlet temperature of about $60{ }^{\circ} \mathrm{C}$. In a few cases, the fan was turned on to add an external force to blow the outlet air at a constant velocity
Table 1 The instrument's characteristics

\begin{tabular}{|c|c|c|c|}
\hline Instrument & Brand and model & Range & Accuracy \\
\hline $\begin{array}{l}\text { Temperature and humidity } \\
\text { sensor }\end{array}$ & Elma DT171 & $\begin{array}{l}-40 \text { to } 70^{\circ} \mathrm{C} \\
0 \text { to } 100 \% \text { R.H. }\end{array}$ & $\begin{array}{l} \pm 1^{\circ} \mathrm{C} \\
\pm 3.5 \%\end{array}$ \\
\hline Digital anemometer & $\begin{array}{l}\text { Benetech GM816A } \\
\text { Electronic Digital } \\
\text { Anemometer LCD Pocket } \\
\text { Smart Air Velocity Meter, } \\
\text { Thermometer, } \\
\text { Wind Speed, Temperature } \\
\text { Tester }\end{array}$ & $\begin{array}{l}0 \sim 30 \mathrm{~m} / \mathrm{s} \\
-10 \sim 45^{\circ} \mathrm{C} \\
\text { Less than } 90 \% \mathrm{RH}\end{array}$ & $\pm 2^{\circ} \mathrm{C}$ \\
\hline Digital Balance & $\begin{array}{l}\text { SF - } 400 \text { Electronic Digital } \\
\text { Weighing }\end{array}$ & $1-10 \mathrm{~kg}$ & $\pm 0.1 \mathrm{~g}$ \\
\hline
\end{tabular}
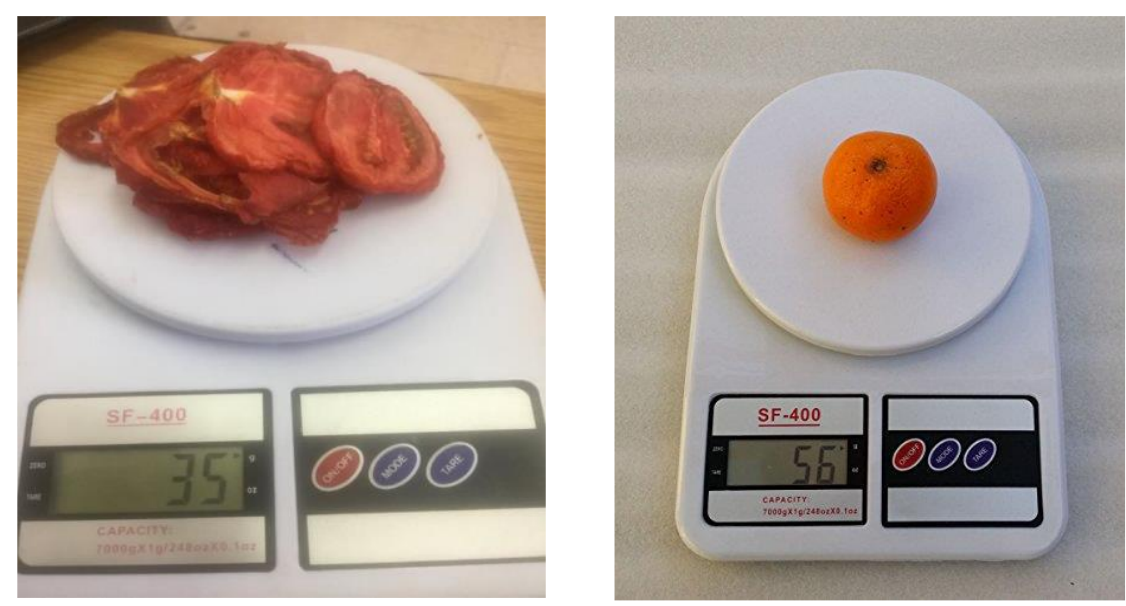

Fig. 2 Weight of tomato samples Measurement 


\subsection{Theoretical analysis}

The instantaneous thermal efficiency of the collector $\left(\eta_{c}\right)$, the thermal efficiency of a solar collector is defined as the ratio of the amount of useful heat collected to the total amount of solar radiation striking the collector's surface during any period.

$$
\eta_{c}=\frac{Q_{d}}{A c I_{T}}=\frac{m c p\left(T_{c o}-T_{c i}\right)}{A c I_{T}}
$$

Where $m$ is the airflow rate $(\mathrm{kg} / \mathrm{s}), T_{c i}$, and $T_{c o}$ are the collector inlet and outlet air temperature $\left({ }^{\circ} \mathrm{C}\right), C p$ is the specific heat of the air, and $I_{. T}$ is incident solar radiation $\left(\mathrm{W} / \mathrm{m}^{2}\right), A_{c}$ is collector area $\left(\mathrm{m}^{2}\right)$.

Moisture Content (M.C.), the moisture content, wet basis, is given as:

$$
\text { M.C. }=\frac{M_{1}-M_{2}}{M_{1}}
$$

Where $M_{1}$ is the mass of the sample before drying., $M_{2}$ is the mass of the sample after drying, percentage of moisture content loss (\%M.C.), and is given by:

$$
\% \text { M.C. }=\frac{\text { initial mass }- \text { final mass }}{\text { initial mass }} \times 100
$$

The Amount of moisture $\left(M_{w}\right)$, humidity is to be removed from a given quantity of wet tomato slices in $\mathrm{kg}$ in a specified time was calculated using the following equations:

$$
M_{w}=\frac{m_{p}\left(M_{i}-M_{f}\right)}{\left(100-M_{f}\right)}
$$

where $m_{p}$ is the initial mass of product to be dried in $\mathrm{kg}, M_{i}$ is the initial moisture content, $\%$ wet basis, $M_{f}$ is the final moisture content, \% wet basis.

The heat needed to evaporate the $\mathrm{H}_{2} \mathrm{O}$ content:

$$
Q=M w^{*} h_{f g}
$$

Where $Q$, the amount of energy required for the drying process in $\mathrm{kJ}, M_{w}$ the mass of water in $\mathrm{kg}$, and $h_{f g}$ is the latent heat of evaporation, $\mathrm{kJ} / \mathrm{kg} \mathrm{H}_{2} \mathrm{O}$.

\begin{tabular}{|c|c|c|c|c|}
\hline Case type & $\begin{array}{l}\text { Weight before } \\
\text { drying }(\mathrm{g})\end{array}$ & $\begin{array}{l}\text { Weight after } \\
\text { drying }(\mathrm{g})\end{array}$ & $\begin{array}{l}\text { Moisture } \\
\text { Loss (g) }\end{array}$ & $\begin{array}{c}\text { Drying } \\
\text { ratio }(\%)\end{array}$ \\
\hline Solar module with nozzle and mirrors at variable outlet velocity & 350 & 35 & 315 & 90 \\
\hline Solar module with nozzle and mirrors at constant outlet velocity & 350 & 47 & 303 & 86.6 \\
\hline Solar module with nozzle/without mirrors at variable outlet velocity & 350 & 52 & 298 & 85.1 \\
\hline Solar module with nozzle/without mirrors at constant outlet velocity & 350 & 57 & 293 & 83.7 \\
\hline Solar module without nozzle and mirrors at variable outlet velocity & 350 & 78 & 272 & 77.7 \\
\hline Solar module without nozzle and mirrors at constant outlet velocity & 350 & 83 & 267 & 76.3 \\
\hline
\end{tabular}

\section{Results and Discussion}

The weights of tomato samples before and after drying were measured. The moisture loss and the drying ratio percentages were calculated for each case, as listed in Table 2.

Table 2 Weights of samples before and after drying and the calculated drying ratio.

The vapor pressure of the trapped water in the tomato will increase due to the concentrated heat. As a result, the drying air's relative humidity will decrease, which will increase the air carrying capacity within the dryer (Sarsavadia et al., 1999). A molecular diffusion mechanism was proposed to govern the water transfer process and adapt the drying data of various organic products (Djebli et al., 2019). Based on the calculated moisture content loss percentages (drying ratio) for each case, it is interesting to note that using the solar module with nozzle and mirrors with variable outlet velocity recorded the highest drying ratio compared to 
other cases. This is because of the combined effect of the addition of nozzle and mirrors. Mirrors have directed the sunlight on the solar collector and, therefore, increase the thermal energy required for drying. Besides, the nozzle enhanced the inlet air velocity to be well distributed on the tomato slices.

Contrary to expectations, we did not find a significant difference between running the experiment using a fan (constant outlet velocity) and depending on the air's natural speed without using a fan (variable outlet velocity). Unlike other research carried out in this area (Boughali et al., 2009; Hegde et al., 2015), we found better results after removing the fan since it was operated on a relatively high speed, $3.28 \mathrm{~m} / \mathrm{s}$, which reduced the contact time between tomato slices and the drying air. Thus it inversely affected the process efficiency. Moreover, running the solar module without any added modifications showed the lowest drying ratios, $77.7 \%$, and $76.3 \%$. The effect of outlet air velocity on the relation of heat power and time for three cases of the natural convection indirect solar dryer is shown in Figure 3. Remarkably, the link between heat power and time for all the cases is worth noting since heat power increases with time till it reaches the peak value at 3:00 pm. After that, the absorbed heat reduces due to the change in air temperature at 5:00 pm. It is apparent from Fig. 3 and higher heat power absorption is achieved when using the modified solar module, including the nozzle and mirrors at variable outlet velocity. Regarding the mirrors, it was noticed that they reach the most significant benefit from it immediately afternoon, where the sun at that hour perpendicular to the solar collector. Surprisingly, the heat power values for using the fan to control the air velocity were lower than the results without using the fan for all the cases. The same explanation as it was mentioned before, due to the inappropriate selected value for velocity. Therefore, it badly affected the solar dryer performance because the fan withdrew the air from the solar dryer, which decreased the contact time between the air and the dried tomato.

The effect of outlet velocity on the relation of effectiveness and time for three cases of the natural convection indirect solar dryer is given in Figure 4. However, the effectiveness represents the ratio between the net absorbed energy to the maximum amount of energy of energy required for the drying process. The most striking result to emerge from the plotted data in Fig. 4 is that higher effectiveness absorption is achieved in the case of variable outlet velocity $92 \%$. It is for the same reasons as discussed before. Similarly, using the fan showed lower effectiveness values, as mentioned in Fig. 3.

The effect of outlet velocity on the relation of outlet temperature and time for three cases of the natural convection indirect solar dryer is shown in Figure 5. According to previous studies, the temperature effect in drying tomatoes is needed in a specific limit (El-Sebaii et al., 2002; Nabnean et al., 2016). From Fig. 5, it can be noticed that the maximum outlet temperature of $55^{\circ} \mathrm{C}$ was recorded for the modified solar module, including the nozzle and mirrors at variable outlet velocity due to the high heat absorbed compared to other cases since the mirrors concentrate the sunlight energy into the collector. As expected, the fan reduced the outlet temperature for all the cases. Figure 6 highlights the change in temperature inside and outside the solar dryer and shows the airflow rate changes. Also, temperature differences could reach up to $20^{\circ} \mathrm{C}$. This considerable temperature difference enhances airflow. 


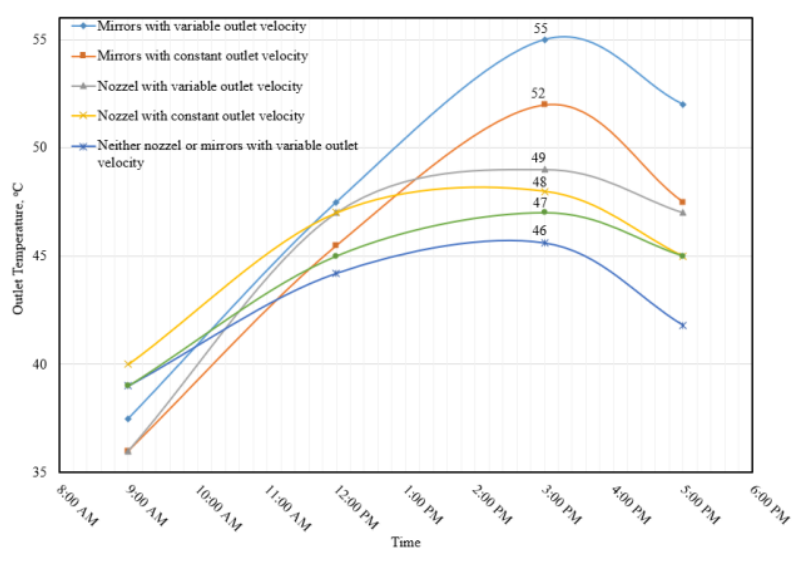

Fig. 5 The outlet temperature of drying process as a function of time and outlet velocity for three cases, the solar module with modifications (nozzle and mirrors), with nozzle without mirrors, and without any addition.

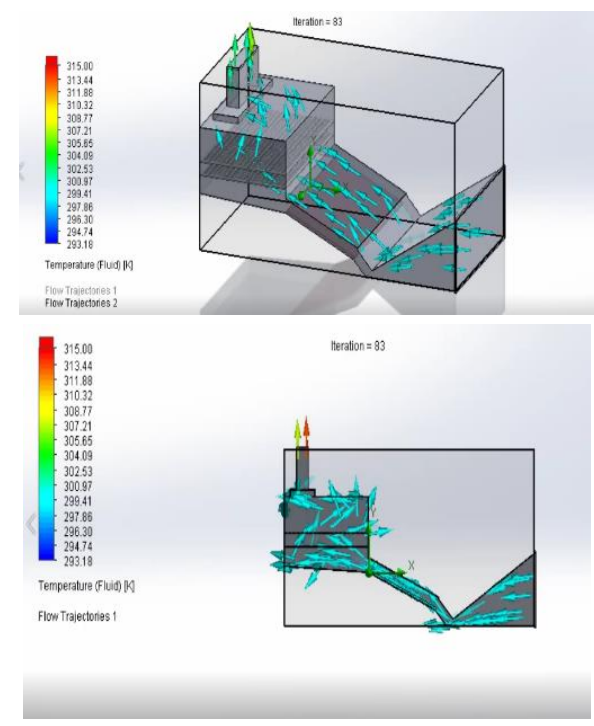

Fig. 6 Simulation for the air flow and the temperature inside and outside the solar dryer

\section{Conclusions}

This study's findings indicate that we have found an innovative design for the natural convection indirect type solar heaters by adding a nozzle at the inlet and mirrors. The addition of mirrors improved the solar dryer performance due to concentrating the heat; the heat power absorbed, and drying effectiveness was higher, and less time was needed for the drying process. The nozzles addition increased the airflow velocity so that less time was needed for the drying process with higher effectiveness; however, the required time and drying effectiveness were not as was expected when using the nozzle without mirrors. Nevertheless, the fan addition was expected to reduce the relative humidity, and the drying process would be better. The results showed that the fan negatively affected the drying process due to its relatively high value.

\section{Nomenclature}

$A_{c}$
$C p$
$h_{f g}$
$\mathrm{I}_{\mathrm{T}}$
$m$
$M . C$
$M_{i}$
$M_{f}$
$M_{l}$
$M_{2}$
$M_{w}$
$m_{p}$
$Q$
$\mathrm{~T}_{\mathrm{ci}}$
$\mathrm{T}_{\mathrm{co}}$
$\eta_{\mathrm{c}}$

$=$ Collector area
$=$ Specific heat of the air
$=$ Latent heat of evaporation
$=$ Incident solar radiation
$=$ Air flow rate
$=$ Moisture content
$=$ Initial moisture content, $\%$ wet basis
$=$ Final moisture content, $\%$ wet basis
$=$ Mass of sample before drying
$=$ Mass of sample after drying
$=$ Amount of moisture to be removed from a given quantity of wet tomato slices
$=$ Initial mass of product to be dried
$=$ Amount of energy required for the drying process
$=$ Collector inlet air temperature
$=$ Collector outlet air temperature
$=$ Instantaneous thermal efficiency of the collector

$\left[\mathrm{m}^{2}\right]$
$\left[\mathrm{J} / \mathrm{kg}^{\circ} \mathrm{C}\right]$
$\left[\mathrm{kJ} / \mathrm{kg} \mathrm{H}_{2} \mathrm{O}\right]$
$\left[\mathrm{W} / \mathrm{m}^{2}\right]$
$[\mathrm{kg} / \mathrm{s}]$
$[-]$
$[\mathrm{kg}]$
$[\mathrm{kg}]$
$[\mathrm{kg}]$
$[\mathrm{kg}]$
$[\mathrm{kg}]$
$[\mathrm{kg}]$
$[\mathrm{kJ}]$
$\left[{ }^{\circ} \mathrm{C}\right]$
$\left[{ }^{\circ} \mathrm{C}\right]$
$[-]$

\section{References}

Alva, G., Lingkun L., Xiang H., and Guiyin F. "Thermal energy storage materials and systems for solar energy applications", Renew. and Sust. Energy Rev., 68, 693-706 (2017).

Al Emam, D. "Farmers union expects higher tomato prices due to crop damage", Jordan Times Newspaper, February 02, (2015). 
Al-Busoul, M. "Design of Fruits Solar Energy Dryer under Climatic Condition in Jordan", J. of Pow. and Energy Eng., 5, 720-726 (2017).

Al-Juamily, K., Khalifa, A., and Yassen, T. "Testing of the performance of a fruit and vegetable solar drying system in Iraq" Desalination, 209, 163-170 (2007).

Alves-Filho, O. "Energy Effective and Green Drying Technologies with Industrial Applications", Chem. Eng. Tran., 70, 145-150 (2018).

Arunsandeep, G., Lingayat, A., Chandramohan, V., Raju, V, and Reddy, K. "A numerical model for drying of spherical object in an indirect type solar dryer and estimating the drying time at different moisture level and air temperature", Int. J. of Green Energy, 15, 189-200 (2018).

Baradey, Y., Hawlader, A., Ismail, F., Hrairi, M., and Rapi, I. "Solar Drying of Fruits and Vegetables" Int. J. of Recent Dev. in Eng. and Tech., 5, 1-6 (2016).

Belessiotis, V., and Delyannis, E. "Solar drying", Solar Ener. Prog. in Solar Energy, 85, 1665-1691 (2011).

Ben slama, R., and Combarnous, M. "Study of orange peels dryings kinetics and development of a solar dryer by forced convection", Solar Energy, $\mathbf{8 5}$, 570-578. (2011).

Bena, B., and Fuller, R. "Natural convection solar dryer with biomass back-up heater", Solar Energy, 72, 75-83 (2002).

Bennamoun, L. "Integration of Photovoltaic Cells in Solar Drying Systems", Drying Tech., 31, 1284-1296 (2013).

Bonaparte, A., Alikhani, Z., Madramootoo, C., and Raghavan, V. "Some quality characteristics of solar-dried cocoa beans in St Lucia", J. of the Sci. of Food and Agri. ,76, 553-558 (1998).

Boughali, S., Bouchekima, B., Mennouche, D., Bouguettaia, H., Bechki, D., and Moussa, H. "Crop drying by indirect active hybrid solar - Electrical dryer in the eastern Algerian Septentrional Sahara", Solar Energy, 83, 2223-2232 (2009).

Djebli, A., Hanini, S., Badaoui, O., and Boumahdi, M. "A new approach to the thermodynamics study of drying tomatoes in mixed solar dryer", Solar Energy, 193, 164-174 (2019).

El-Sebaii, A., Aboulenein, S., Ramadan, M., and El-Gohary, H. "Experimental investigation of an indirect type natural convection solar dryer", Energy Conv. Manag., 43, 2251-2266 (2002).

El-Sebaii, A., and Shalaby, S. "Solar drying of agricultural products: A review", Renew. and Sustain. Energy. Rev., 16, 37-43 (2012).

Erick César, L., Ana Lilia, C., Octavio, G., Isaac, P., and Rogelio, B. "Thermal performance of a passive, mixed-type solar dryer for tomato slices (Solanum lycopersicum)", Renew. Energy, 147, 845-855 (2020).

Esper, A., and Mühlbauer, W. "Solar drying - an effective means of food preservation", Renew. Energy, Energy Eff., Pol. and the Env., 15, 95-100 (1998).

Hassanain, A. "Simple solar drying system for banana fruit" World J. of Agri. Sci., 5, 446-455 (2009).

Hawlader, M., Perera, C., and Tian, M. "Comparison of the retention of 6-gingerol in drying of ginger under modified atmosphere heat pump drying and other drying methods", Drying Tech., 24, 51-56 (2006).

Hegde, V., Hosur, V., Rathod, S., Harsoor, P., and Narayana, B. "Design, fabrication and performance evaluation of solar dryer for banana", Energy Sustain. and Soc., 5, 5-23 (2015).

Kumar, R., and Rosen, M. "A critical review of photovoltaic-thermal solar collectors for air heating", Appl. Energy, 88, 3603-3614 (2011).

Lingayat, A., Chandramohan, V., and Raju, V. "Design, Development and Performance of Indirect Type Solar Dryer for Banana Drying", Energy Procedia, International Conference on Recent Advancement in Air Conditioning and Refrigeration, 109, 409-416 (2017).

Maiti, S., Patel, P., Vyas, K., Eswaran, K., and Ghosh, P. "Performance evaluation of a small scale indirect solar dryer with static reflectors during nonsummer months in the Saurashtra region of western India", Solar Energy, 85, 2686-2696 (2011).

Nabnean, S., Janjai, S., Thepa, S., Sudaprasert, K., Songprakorp, R., and Bala, B. "Experimental performance of a new design of solar dryer for drying osmotically dehydrated cherry tomatoes", Renew. Energy, 94, 147-156 (2016).

Parikh, D., and Agrawal, G. "Solar Drying in Hot and Dry Climate of Jaipur", Int. J. of Renew. Energy. Res.- IJRER, 1, 224-231 (2012).

Qasaimeh, A. "Solar Energy Optimization through Seasons: Case Study in Jordan" Smart Grid and Renew. Energy, 3, 275-281 (2012).

Samuel, D. "Convective Flat-plate Solar Heat Collector for Cauliflower Drying", Biosystems Eng., 93, 189-198 (2006).

Sarsavadia, P., Sawhney, R., Pangavhane, D., and Singh, S. "Drying behaviour of brined onion slices", J. of Food Eng., 40, $219-226$ (1999)

Schirmer, P., Janjai, S., Esper, A. Smitabhindu, R., and Mühlbauer, W. "Experimental investigation of the performance of the solar tunnel dryer for drying bananas", Renew. Energy, 7, 119-129 (1996).

Singh, S., Jairaj, K., and Kalaveerakkanavar, S. "The development of solar dryers used for grape drying", The First India International Energy summit, 1 $10(2011)$

Sorour, H., Elmesery, H. "Effect of microwave and infrared radiation on drying of onion slices", Int. J. of Res. in Appl. Nat. and Soc. Sci., 2, 119-130 (2014).

Stiling, J., Li, S., Stroeve, P., Thompson, J., Mjawa, B., Kornbluth, K., and Barrett, D. "Performance evaluation of an enhanced fruit solar dryer using concentrating panels", Energy of Sust. Dev., 16, 224-230 (2012).

Tiris, C., Tiris, M., and Dincer, I. "Experiments on a new small-scale solar dryer", Appl. Thermal Energy, 16, 183-187 (1996).

Turkiewicz, I., Wojdyło, A., Lech, K., Tkacz, K., and Nowicka, P. "Influence of different drying methods on the quality of Japanese quince fruit", $L W T$ Food Sci. and Tech., 114, 108416 (2019).

Wilkins, R., Brusey, J., and Gaura, E. "Modelling uncontrolled solar drying of mango waste", J. of Food Eng., 237, 44-51 (2018).

Zhang, M., Tang, J., Mujumdar, A., and Wang, S. "Trends in microwave-related drying of fruits and vegetables", Trends Food Sci. and Tech., 17, 524-534 (2006). 